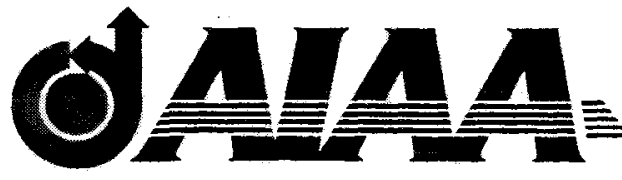

A00-36633

AIAA 2000-3422

\title{
An Investigation of Internal Ion Number Density and Electron Temperature Profiles in a Laboratory-Model Hall Thruster
}

James M. Haas and Alec D. Gallimore Plasmadynamics and Electric Propulsion Laboratory University of Michigan Ann Arbor, MI USA

$36^{\text {th }}$ AIAA/ASME/SAE/ASEE Joint Propulsion Conference July 17-19, 2000 Huntsville, AL

For permission to copy or to republish, contact the American Institute of Aeronautics and Astronautics, 1801 Alexander Bell Drive, Suite 500, Reston, VA, 20191-4344. 


\title{
An Investigation of Internal Ion Number Density and Electron Temperature Profiles in a Laboratory-Model Hall Thruster
}

\author{
James M. Haas* and Alec D. Gallimore ${ }^{\dagger}$ \\ Plasmadynamics and Electric Propulsion Laboratory \\ Department of Aerospace Engineering \\ The University of Michigan \\ Ann Arbor, MI 48109 USA
}

\begin{abstract}
Experiments have been conducted at the University of Michigan Plasmadynamics and Electric Propulsion Laboratory (PEPL) to investigate the acceleration and ionization mechanisms in the P5 laboratory-model Hall thruster. A cylindrical, double Langmuir probe was used to measure electron temperature and ion number density in the discharge chamber of the P5. Probe residence times inside the thruster, and hence thruster perturbation, were minimized by use of PEPL's High-Speed Axial Reciprocating Probe (HARP) system. Discharge voltage for this experiment was fixed at $300 \mathrm{~V}$ and two discharge current settings were considered: $5.4 \mathrm{~A}(1.6 \mathrm{~kW})$ and $10 \mathrm{~A}(3 \mathrm{~kW})$. Axial profiles of temperature and number density at multiple radial positions spanning the width of the discharge channel are presented for the two cases along with previously measured profiles of the radial magnetic field and plasma potential. At $1.6 \mathrm{~kW}$, the number density exhibited a dual-peak axial profile indicating two regions of ionization. The maximum temperature and number density was approximately $38 \mathrm{eV}$ and $2.1 \times 10^{18} \mathrm{~m}^{-3}$, respectively. This structure essentially disappeared at $3 \mathrm{~kW}$, with a single number density peak of $2.8 \mathrm{e} 10^{18}$. Electron temperature reached a maximum of $32 \mathrm{eV}$ at roughly the same axial location.
\end{abstract}

\section{INTRODUCTION}

The role of the Hall thruster as a primary propulsion device continues to expand and evolve as new missions are developed which can benefit directly from the Hall thruster's unique combination of thrust and specific impulse. Along with this changing role comes the need to scale existing thrusters to both higher and lower power levels without sacrificing the thruster's inherent performance characteristics.

Central to this idea of efficient scaling is the need to fully understand the Hall thruster ionization and acceleration mechanisms. This will be accomplished by a thorough mapping of plasma parameters inside the discharge chamber. The resulting data will enable the development of accurate computer models, which will be invaluable in generating the next generation of high-efficiency Hall thrusters.
Toward this end, the University of Michigan Plasmadynamics and Electric Propulsion Laboratory (PEPL) has developed a comprehensive experimental program aimed at fully exploring the underlying physics of the Hall thruster. The centerpiece of this effort is the P5, a $5 \mathrm{~kW}$ laboratory-model Hall thruster. The P5 has been shown to have performance characteristics very similar to commercially available, state-of-the-art thrusters. ${ }^{1}$ It was designed specifically to facilitate internal plasma parameter measurements. As part of the same program, a High-Speed Axial Reciprocating Probe (HARP) system was assembled to allow rapid positioning of electrostatic probes inside the thruster. Using the HARP, probe residence times under 100 $\mathrm{ms}$ are routinely and consistently achieved. Correspondingly, perturbations to the discharge current during data collection are generally less than $10 \%{ }^{2}$

\footnotetext{
* Graduate Student, Student Member, AlAA.

${ }^{\dagger}$ Associate Professor, Director of Lab, Associate Fellow, AIAA.

Copyright $(\mathrm{C} 2000$ by James M. Haas

Published by the American Institute of Aeronautics and Astronautics with permission.
} 


\section{OBJECTIVE}

The objective of this research is to measure the electron temperature and ion number density inside the discharge chamber of a Hall thruster while avoiding significant perturbation to thruster operation. The resulting data are combined with previous measurements of the axial electric field and radial magnetic field to further extend our understanding of the magnitude and spatial structure of the ionization and acceleration regions.

\section{EXPERIMENTAL SET-UP}

\section{Thruster}

The thruster used is the University of Michigan/Air Force Research Laboratory P5 $5 \mathrm{~kW}$ laboratory-model Hall thruster. This thruster was developed specifically to provide extensive diagnostic access to the discharge chamber. Compared to smaller thrusters, the P5 provides a larger discharge chamber for better spatial resolution for electrostatic probes as well as a lower power density to reduce heat flux to the probe. Thrust, specific impulse, and efficiency have been measured and correspond very closely to commercially available thrusters. Performance characteristics and plasma parameter profiles in the plume have been reported in a previous work. ${ }^{1}$ The P5 incorporates a lanthanum hexaboride (LaB6) cathode.

Thruster discharge voltage was fixed at $300 \mathrm{~V}$ for all experiments. Two discharge current levels were considered: $5.4 \mathrm{~A}$ and $10 \mathrm{~A}$. These corresponded to anode mass flow rates of $63 \mathrm{sccm}$ and $112 \mathrm{sccm}$, respectively. Cathode mass flow rate remained constant at $6 \mathrm{sccm}$.

\section{Vacuum Chamber}

All experiments were conducted in the University of Michigan's $6 \mathrm{~m}$ diameter by $9 \mathrm{~m}$ long Large Vacuum Test Facility (LVTF). The pumping system consists of four CVI model TM-1200 ReEntrant Cryopumps providing a measured xenon pumping speed of $140,000 \mathrm{~V} / \mathrm{s}$. The ultimate base pressure of the facility is $2 \times 10^{-7}$ Torr. The operating pressures for this experiment were $5.5 \times 10^{-6}$ Torr and $9.6 \times 10^{-6}$ Torr when corrected for xenon and corresponded to discharge currents of $5.4 \mathrm{~A}$ and 10.0 A, respectively. Details of the facility have been presented in a previous work. ${ }^{1}$

\section{Positioning System}

The double probe is positioned inside the Hall thruster discharge chamber using the PEPL HARP system. The HARP system allows the probe to be inserted into, and removed from, the thruster on a time scale under $100 \mathrm{~ms}$. This allows measurements to be made with very little perturbation to thruster operation. The extent of thruster perturbation is determined by monitoring the discharge current during probe movement. Use of the double probe caused a slight perturbation in the discharge current but this remained less than $10 \%$ of the nominal discharge current value during all measurements. Double probe data were collected during both insertion and removal of the probe and agreed reasonably well for most sets of data. However, data from the outward sweep generally exhibited more noise due to the presence of the probe insulator body in the channel. It was concluded that the inward sweep was more representative of the true data. Therefore all data presented, unless otherwise noted, are from the inward sweep.

Figure 1 shows the area inside the discharge chamber where electron temperature and ion number density were measured. The exit plane is defined as the end of the discharge channel.

Radial movement is accomplished by mounting the thruster on a linear table. Between axial sweeps with the HARP system, the thruster is moved radially such that a 2-D cross section of the discharge chamber and near-field region is covered. Note that the axial position throughout this paper corresponds to the tip of the double probe electrodes.

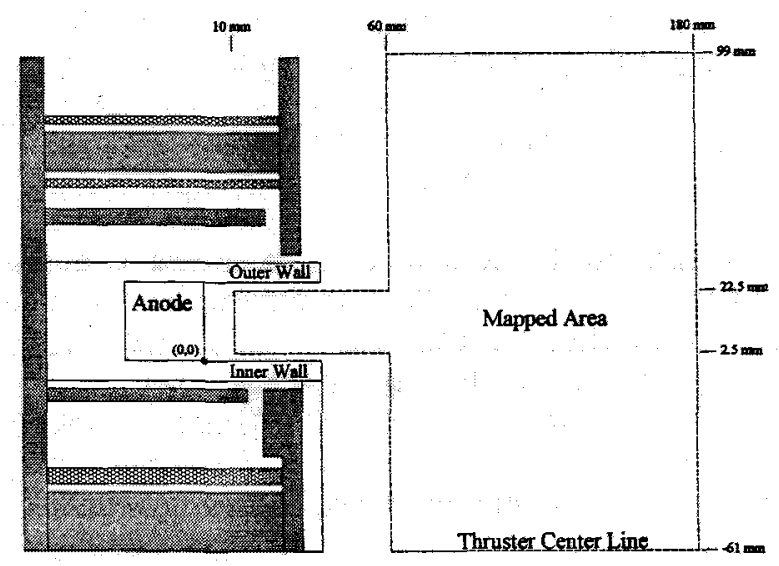

Figure 1. The internal area mapped begins approximately $10 \mathrm{~mm}$ from the anode face, extends $2 \mathrm{~cm}$ downstream of the exit plane, and comes to within $2.5 \mathrm{~mm}$ of the inner and outer walls of the discharge chamber. The larger area extenus axially from 2 to $14 \mathrm{~cm}$ downstream of the exit plane and radially from the thruster centerline to the outer edge of the pole piece. 


\section{Probe Construction and Design Considerations}

Langmuir probes provide one of the best means for making spatially resolved measurements of electron temperature and number density in plasmas. While the basic probe theory in an ideal plasma is quite simple to implement, the plasma characteristics in the discharge channel of the Hall thruster create significant difficulties in collecting and interpreting probe data. Therefore, great care must be taken in choosing the shape, size, and orientation of the probe due to the presence of streaming ions, high plasma potentials and potential gradients, and large radial magnetic fields. Fortunately, many of these effects can be made negligible with proper consideration.

Langmuir probes are generally classified according to two parameters: the number and the shape of the electrodes. Planar, cylindrical, and spherical probes with one to four electrodes have been used in a wide range of plasmas and the theory of their operation is extensive. Spherical probes were immediately rejected for this experiment because of the difficulty in their construction, particularly of sizes small enough to provide good spatial resolution inside the thruster. Both planar and cylindrical probes are easily constructed at very small sizes and can be configured as single, double or triple probes.

Recalling that the probe is inserted and removed from the thruster in approximately $100 \mathrm{~ms}$, the triple probe is very attractive because it does not require a voltage sweep. ${ }^{3}$ It needs only a fixed voltage between two electrodes while the third floats. However, in this case size again becomes an issue. Because of the wide range of parameters in the thruster, the Debye length can grow considerably, necessitating a large separation between electrodes. This leads to a large overall probe size that can severely perturb the thruster and reduces the resolution of the measurement.

Of the single and double probe configurations, the double probe provides several advantages in the Hall thruster. The single probe potential is biased with respect to some fixed reference; generally electrical or chamber ground. The bias range starts highly negative (ion saturation) and extends to the plasma potential (electron saturation). In the Hall thruster, plasma potential ranges from tens of volts in the near-field region to several hundreds of volts (discharge voltage) near the anode. ${ }^{4}$ This greatly complicates the experimental setup as the sweep voltage range is quite large and changes dramatically throughout the discharge chamber. This need to bias the probe at or beyond the plasma potential also creates serious perturbation problems. The electron saturation current can be several orders of magnitude larger than the ion saturation current and drawing this much current from the plasma can cause serious perturbations to thruster operation.

The double probe eliminates most of the problems associated with the single probe, A voltage sweep is still required but it is between two electrodes which float as a whole, one above the floating potential and one below. The electron current to a given electrode is limited by the ion saturation current of the other electrode and because the probe is floating, the net current to the probe is zero. This results in very little perturbation to the plasma. Also, because the current is limited to the ion saturation current, a much smaller voltage sweep range is required.

The decision to use a double probe dictated the final choice of a cylindrical geometry. As stated above, the current collected by a double probe electrode is limited to the ion saturation current. For the temperatures and number densities expected $\left(\sim 10-50 \mathrm{eV}, 1-5 \times 10^{18} \mathrm{~m}^{-3}\right)$, this is on the order of several 10-100 microamps, which can be quite difficult to measure accurately. This is particularly difficult in chambers as large as the LVTF because the large line lengths between the probe and external data acquisition system introduce a large amount of capacitance. $^{3}$ The current magnitude, of course, depends on the probe size as well. Therefore, the cylindrical probe was chosen to maximize the ion saturation current.

The magnetic field in the thruster influences probe measurements because it constrains the motion of the charged particles. For the conditions in the $\mathrm{P5}$, the ions are essentially unmagnetized based on their gyroradius being much larger than the probe dimensions. The electrons, on the other hand, have much smaller gyroradii owing to their much smaller mass. The magnetic field effect manifests itself in two ways; it reduces the electron saturation current ${ }^{6}$ and causes anisotropy of the electron energy distribution function (EEDF) ${ }^{7}$ Reduction of the electron saturation current causes the electron number density to be substantially underpredicted. This is not an issue with the double probe as number density is inferred from the ion saturation current. Electron temperature can still be determined by standard theory from the slope of the I-V characteristic.

The question of EEDF anisotropy has been shown by Aikawa to depend not on magnetic field 
(B) itself but on the ratio $B / p_{0}$, where $p_{0}$ is the pressure in the discharge chamber. ${ }^{7}$ It was shown experimentally by Aikawa that anisotropy of the $\mathrm{EEDF}$ is on the order of several $\mathrm{B} / \mathrm{p}_{\mathrm{o}}$. In the $\mathrm{P} 5, \mathrm{~B}$ has a maximum of $0.02 \mathrm{~T}$ and the pressure in the discharge chamber is approximately $0.133 \mathrm{~Pa}$. This yields a $\mathrm{B} / \mathrm{p}_{\mathrm{o}}$ value not exceeding $1.5 \times 10^{-1} \mathrm{~T} / \mathrm{Pa}$ for these experiments. Therefore, there was expected to be no substantial anisotropy in the EEDF in this experiment.

The final consideration in probe design was the orientation of the electrode axis. If the probe axis is aligned with the thruster axis, the electrode could see a potential gradient along its length where the electric field is large. This distorts the probe characteristic, introducing a rounding of the "knee" at the space potential. ${ }^{6}$ However, as previously noted, the double probe does not rely on measuring the electron saturation current so this effect is negligible. Alignment with the thruster axis also aligns the axis of the probe with the flowing ions and introduces the problem of "end effects". "End effects" can be minimized by making the probe length to diameter ratio sufficiently large. This alignment has the added benefit of orienting the probe perpendicular to the radial magnetic field which further minimizes the effect of the magnetic field on electron collection. ${ }^{6}$ Conversely, by orienting the probe axis perpendicular to the flow, the high speed ions distort the electron sheath and the electron temperature can no longer be determined by standard theory. ${ }^{8}$

In summation, it was determined that a double cylindrical probe aligned with the axis of the thruster essentially eliminates the problem of the magnetic field effect on electron collection. Several probes were built and tested and the various parameters adjusted as more experience was gained. The final iteration is presented in Figure 2.

Each tungsten electrode had a diameter of 0.25 $\mathrm{mm}$ and a length of $2.0 \mathrm{~mm}$. The electrodes were insulated from each other and the plasma by alumina tubing and cemented in place with an alumina adhesive. The dimensions were chosen to balance the need for sufficiently large collected currents and length to diameter ratios (larger electrodes) with the need for sufficient resolution and minimal thruster perturbation (smaller electrodes).

As mentioned earlier, one difficulty with the double probe is that it requires a voltage sweep to determine the I-V characteristic. Under less demanding circumstances, this can be accomplished with a bi-polar supply and function generator. The difficulty here is that the probe, and hence any required circuitry, is required to float. The floating potential can swing several hundred volts as the probe is moved into the channel. This creates a problem for all of the electronics and can result in significant errors in the measured current if there is any appreciable stray capacitance in the circuit. This problem was minimized by careful attention to the circuit construction to minimize stray capacitance and by using batteries to supply the bias voltage. A potentiometer was attached to the battery output so that the bias could be adjusted. The probe and circuit were isolated from the data collection equipment by two AD210 isolation amplifiers. Figure 3 shows the probe circuit.

For each fixed bias point, the probe current and voltage were measured at each spatial location in the $2-\mathrm{D}$ domain of Figure 1. The resulting data were then reassembled to get a single current-voltage trace at each point in the domain. Figure 4 shows a representative double probe trace $14 \mathrm{~cm}$ downstream of the exit plane at the center of the discharge channel at a thruster operating condition of $300 \mathrm{~V}$ and $10 \mathrm{~A}$.
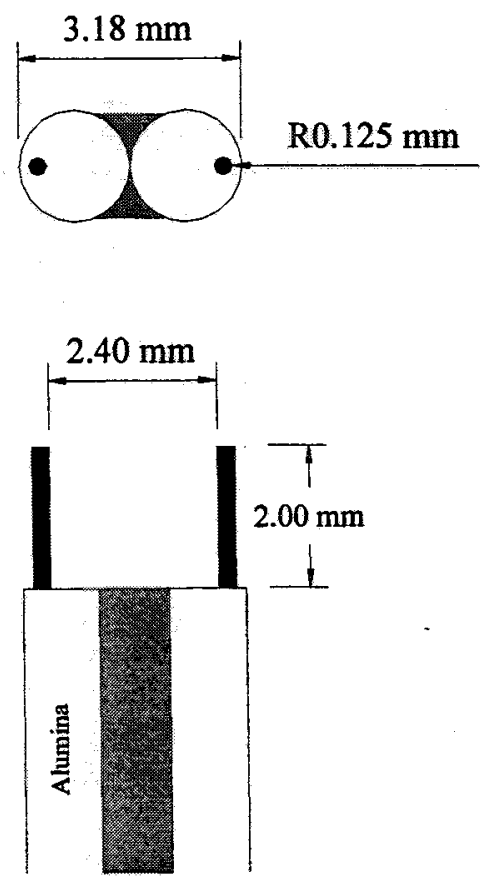

Figure 2. The double cylindrical floating probe. 


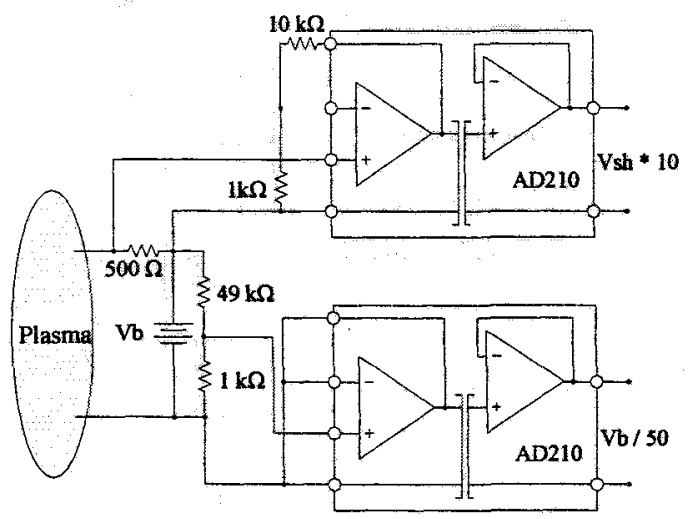

Figure 3. Double probe circuit.

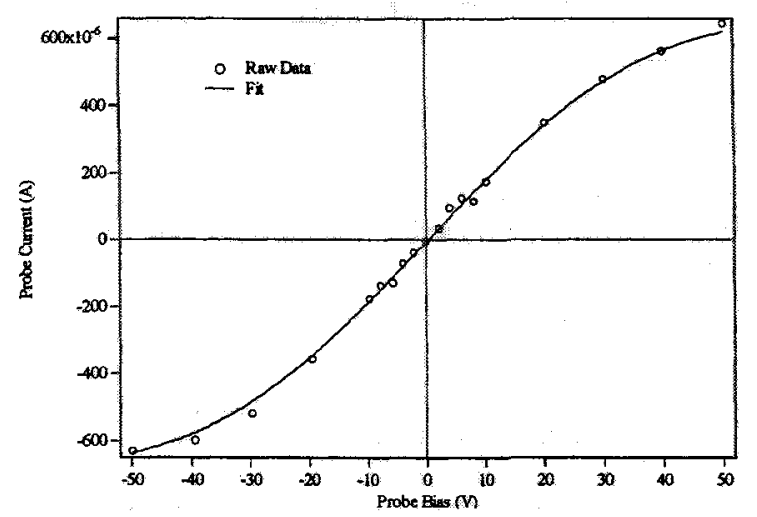

Figure 4. Representative probe characteristic at an axial position of $32 \mathrm{~mm}$ along the center of the discharge channel. Data were collected at voltage steps of $10 \mathrm{~V}$, except for the range $-10 \mathrm{~V}$ to $+10 \mathrm{~V}$ where the voltage step was $2 \mathrm{~V}$.

In order to obtain the electron temperature and ion number density, the data were fit to the theoretical current-voltage expression for a symmetric double probe.

$$
I=I_{\text {sat }} \cdot \tanh \left(\frac{V}{2 T_{e}}\right)+A \cdot V+B
$$

In equation (1), $T_{e}$ is the electron temperature in $\mathrm{eV}, \mathrm{I}_{\mathrm{sat}}$ is the ion saturation current to either probe, the parameter $A$ accounts for sheath expansion in the ion saturation region, and the parameter $B$ reflects any offset current due to stray capacitance. ${ }^{5}$ The scientific graphing package Igor was used to fit this equation to the experimental data using a LevenbergMarquardt method.

\section{RESULTS}

Thruster discharge voltage was fixed at $300 \mathrm{~V}$ for all measurements and two discharge current settings were investigated: $5.4 \mathrm{~A}$ and $10 \mathrm{~A}$. Data were collected continuously as the probe was swept axially into and out of the thruster at five radial positions. The data were then interpolated to provide a current-voltage characteristic every millimeter in the axial direction. Note that the data begins at an axial position of $10 \mathrm{~mm}$, this being the closest the probe could be positioned to the anode due to problems with probe overshoot. The data also stops approximately $2.5 \mathrm{~mm}$ from the inner and outer walls in order to allow clearance of the ceramic insulator.

Figures 5 - 9 show the electron temperature and ion number density at $5.4 \mathrm{~A}(1.6 \mathrm{~kW})$ for five different radial positions inside the discharge channel: $2.5 \mathrm{~mm}, 7.5 \mathrm{~mm}, 12.5 \mathrm{~mm}, 17.5 \mathrm{~mm}$, and $22.5 \mathrm{~mm}$. These positions are referenced to the inner wall of the channel. The radial magnetic field and axial potential field profiles at the same radial position are included for comparison. The scale for each variable is kept constant on each plot to facilitate comparison at different radial position. The maximum temperature was approximately $38 \mathrm{eV}$ and the number density did not exceed $2.1 \times 10^{18} \mathrm{~m}^{-3}$.

The five radial profiles were combined into a single matrix and the resulting contour plots are shown in Figures 10 and 11. In addition to the data in the discharge channel, temperature and number density data were collected in the near-field region between thruster centerline and the outer edge of the front pole piece. These data are included in the contour plots of Figures 10 and 11.

Figures $12-16$ show the electron temperature and number density with the thruster operating at 10 A $(3 \mathrm{~kW})$. Data are presented for the same five radial positions as the $5.4 \mathrm{~A}$ case. The maximum temperature and number density observed were approximately $32 \mathrm{eV}$ and $2.8 \mathrm{e}^{10} \mathrm{~m}^{18} \mathrm{~m}^{-3}$, respectively. These data, along with additional near-field data, are also presented in contour form in Figures 17 and 18. 


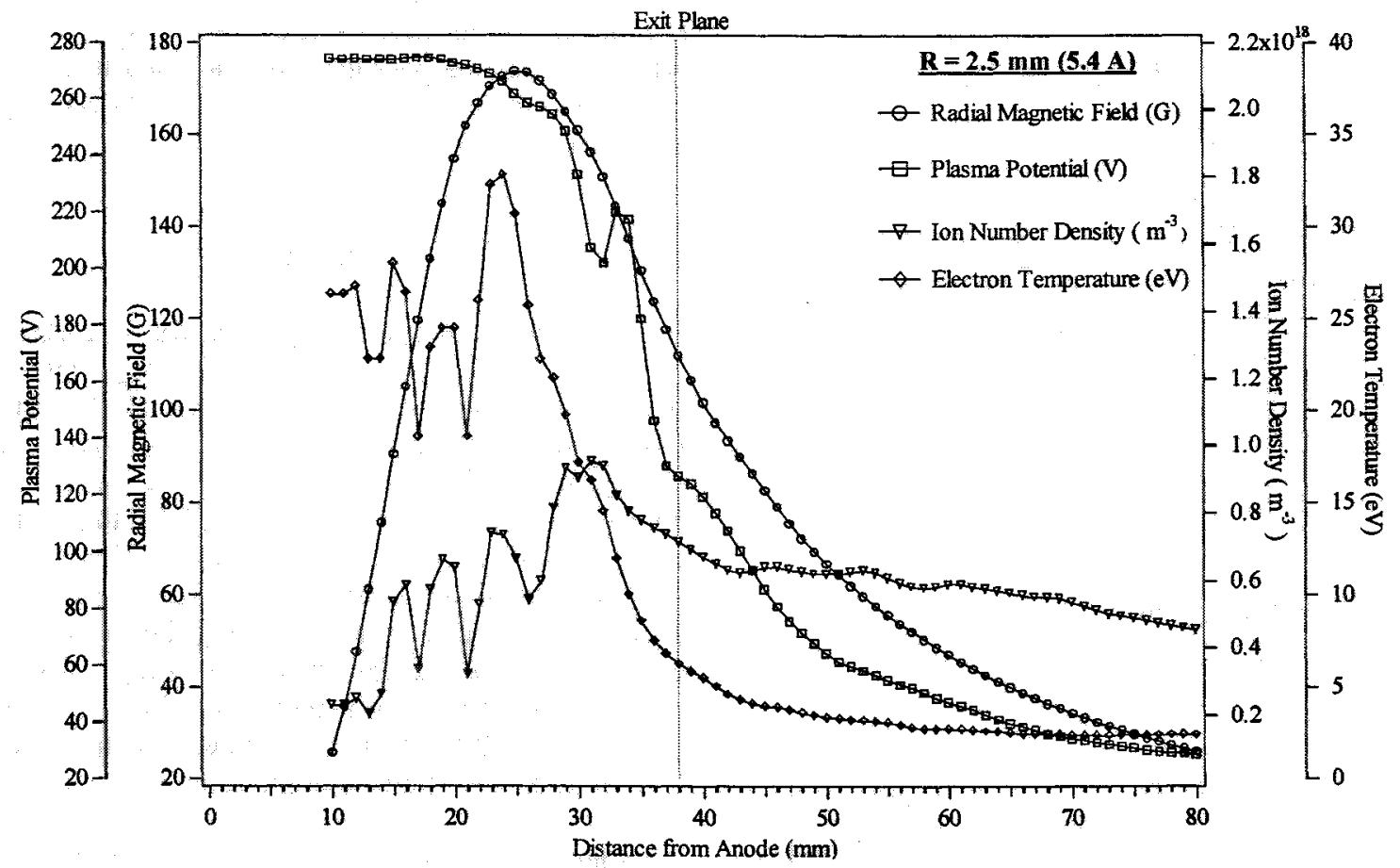

Figure 5. Radial magnetic field, plasma potential, ion number density, and electron temperature profiles in the discharge chamber at an operating condition of $300 \mathrm{~V}, 5.4 \mathrm{~A}$. These data correspond to a radial position $2.5 \mathrm{~mm}$ from the inner wall.

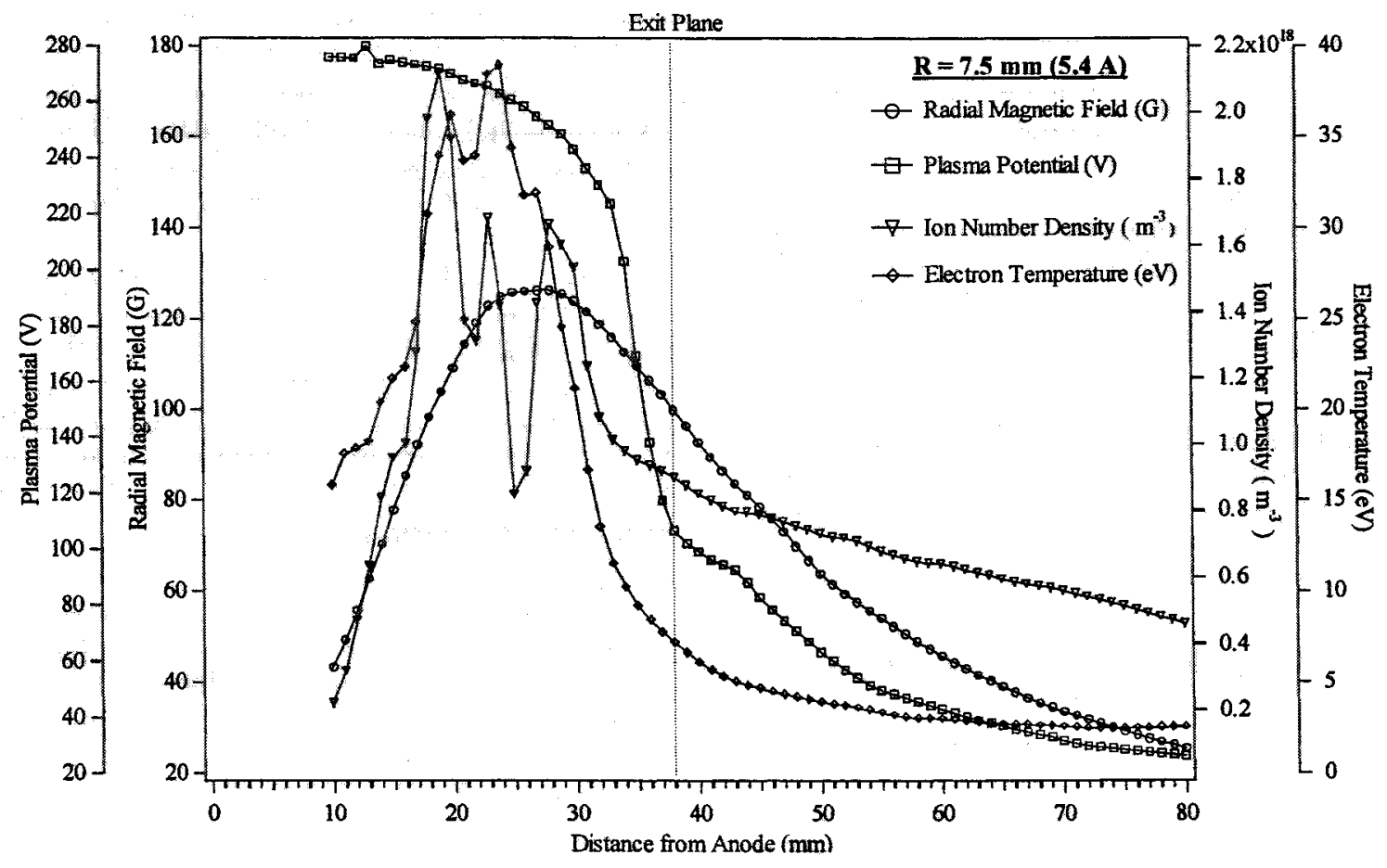

Figure 6. Radial magnetic field, plasma potential, ion number density, and electron temperature profiles in the discharge chamber at an operating condition of $300 \mathrm{~V}, 5.4 \mathrm{~A}$. These data correspond to a radial position $7.5 \mathrm{~mm}$ from the inner wall. 


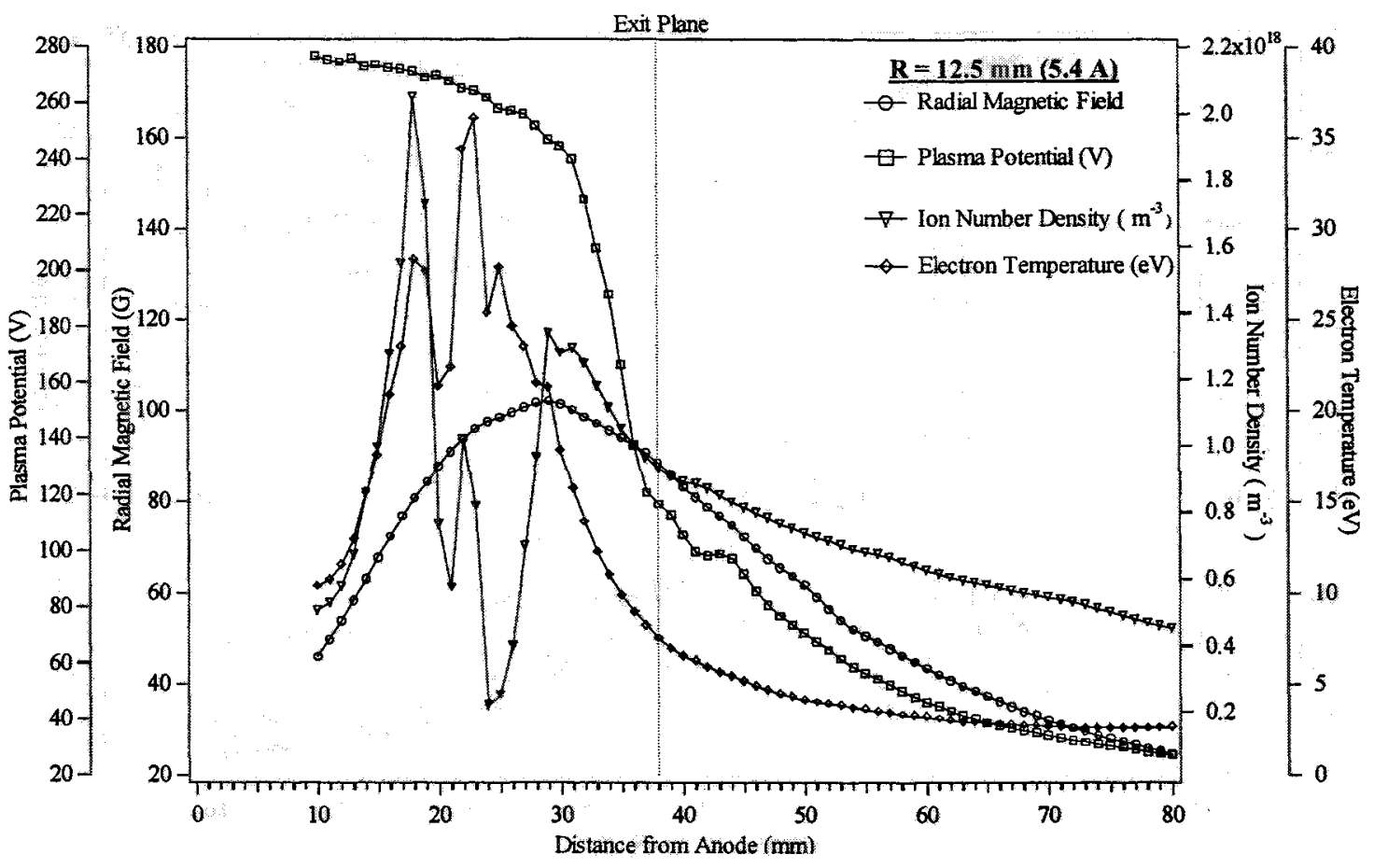

Figure 7. Radial magnetic field, plasma potential, ion number density, and electron temperature profiles in the discharge chamber at an operating condition of $300 \mathrm{~V}, 5.4 \mathrm{~A}$. These data correspond to a radial position $12.5 \mathrm{~mm}$ from the inner wall.

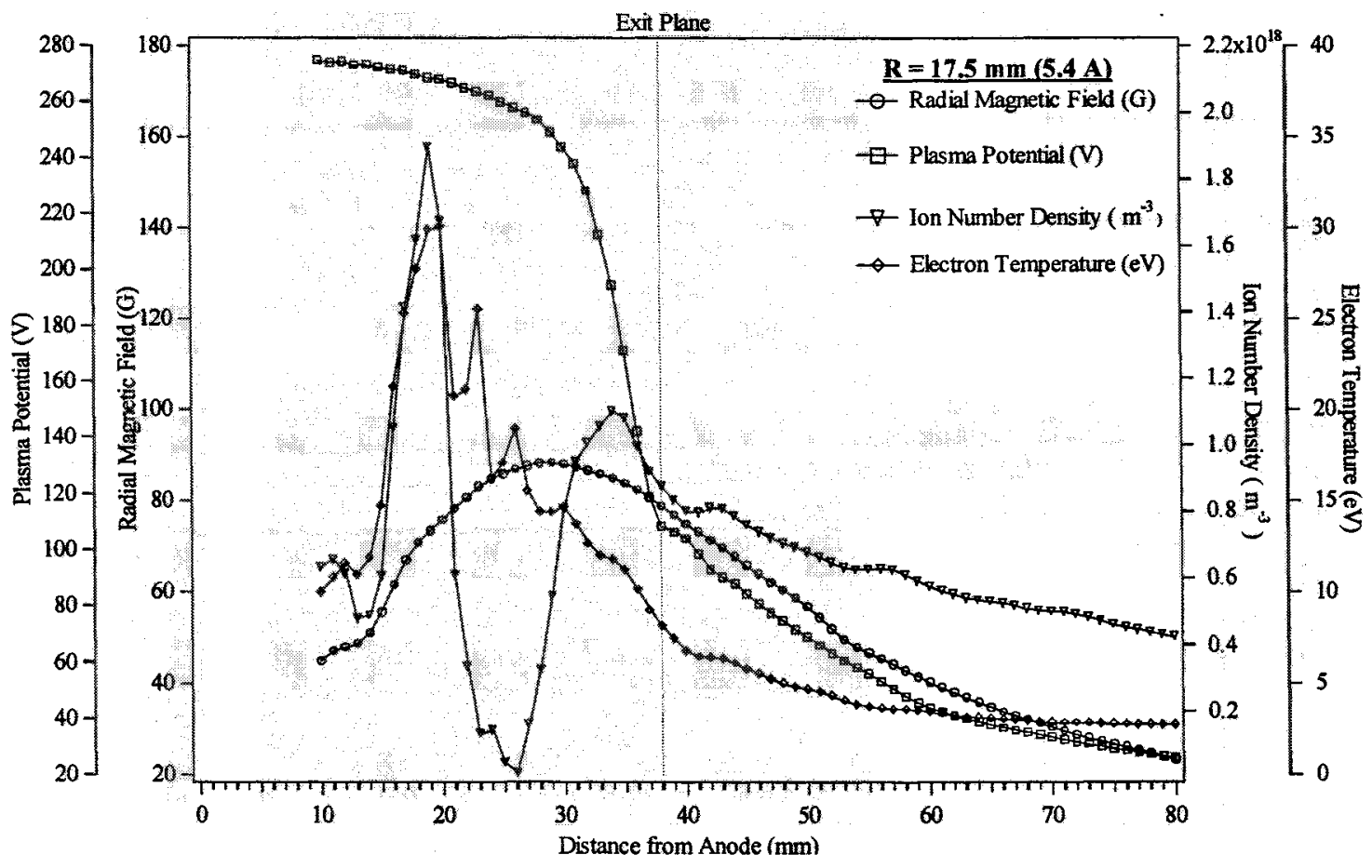

Figure 8. Radial magnetic field, plasma potential, ion number density, and electron temperature profiles in the discharge chamber at an operating condition of $300 \mathrm{~V}, 5.4 \mathrm{~A}$. These data correspond to a radial position 17.5 $\mathrm{mm}$ from the inner wall. 


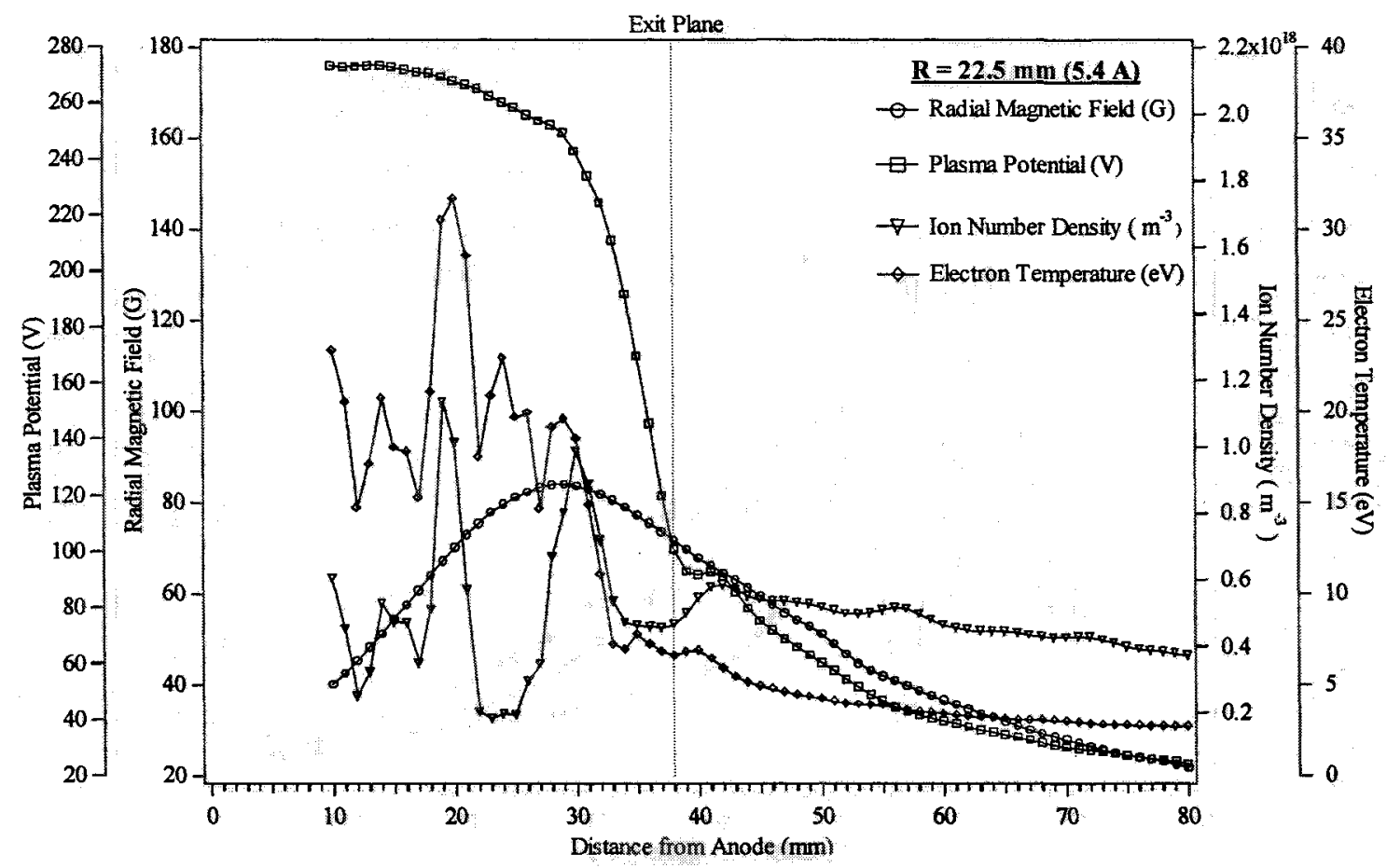

Figure 9. Radial magnetic field, plasma potential, ion number density, and electron temperature profiles in the discharge chamber at an operating condition of $300 \mathrm{~V}, 5.4 \mathrm{~A}$. These data correspond to a radial position $22.5 \mathrm{~mm}$ from the inner wall.

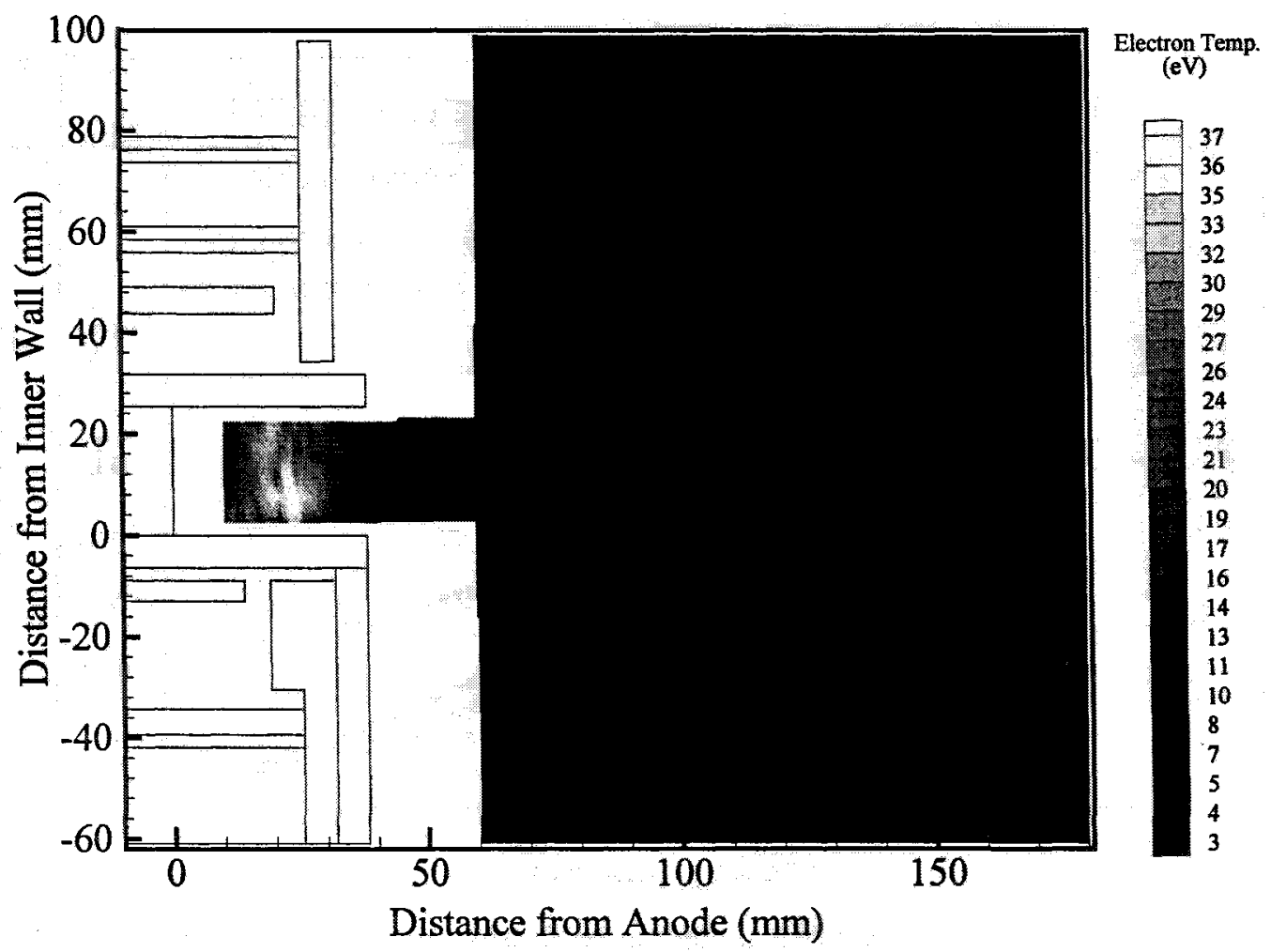

Figure 10. Contours of electron temperature at a thruster operating condition of $300 \mathrm{~V}$ and $5.4 \mathrm{~A}$ 


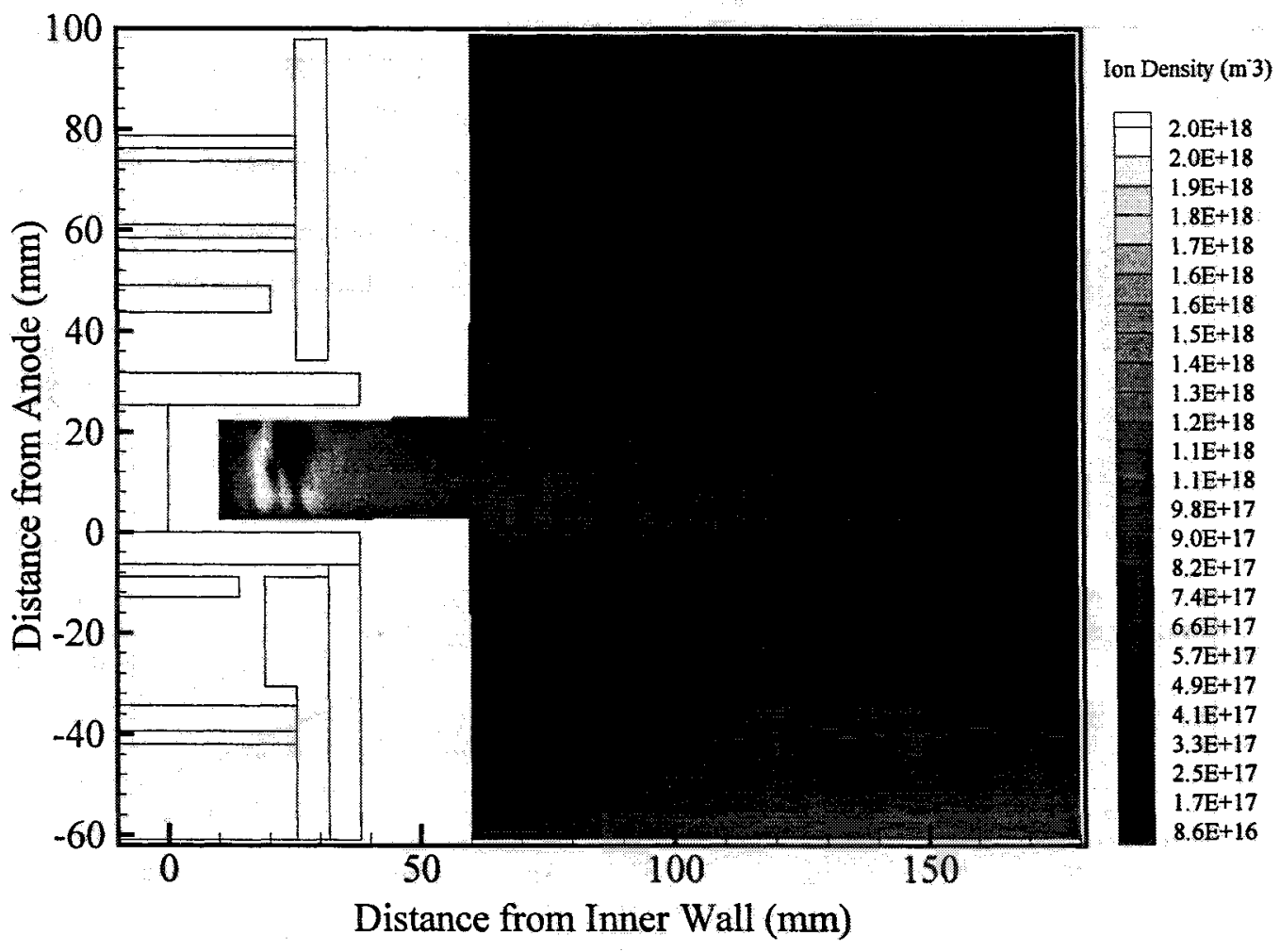

Figure 11. Contours of ion number density at a thruster operating condition of $300 \mathrm{~V}$ and $5.4 \mathrm{~A}$.

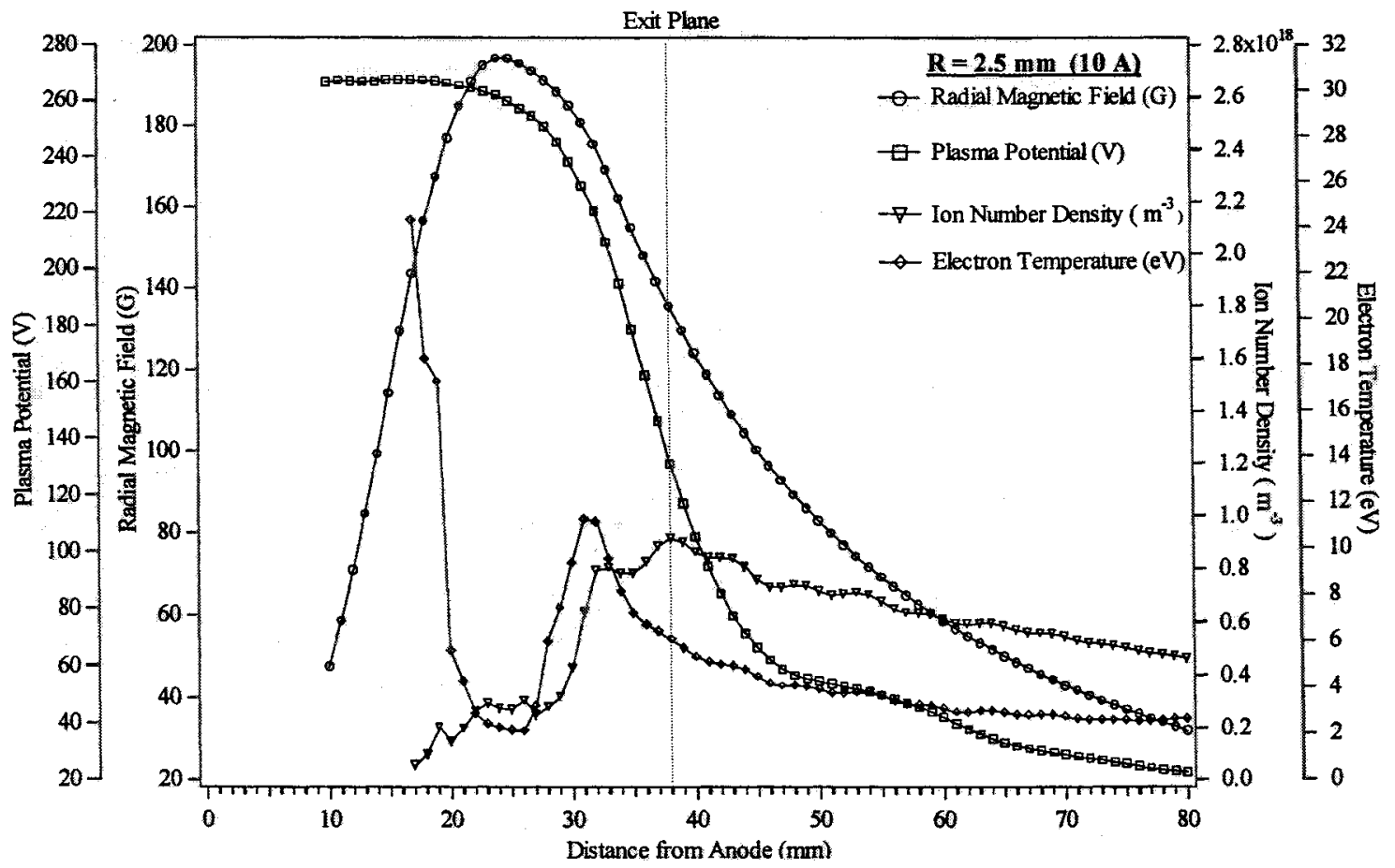

Figure 12. Radial magnetic field, plasma potential, ion number density, and electron temperature profiles in the discharge chamber at an operating condition of $300 \mathrm{~V}, 10 \mathrm{~A}$. These data correspond to a radial position $2.5 \mathrm{~mm}$ from the inner wall. 


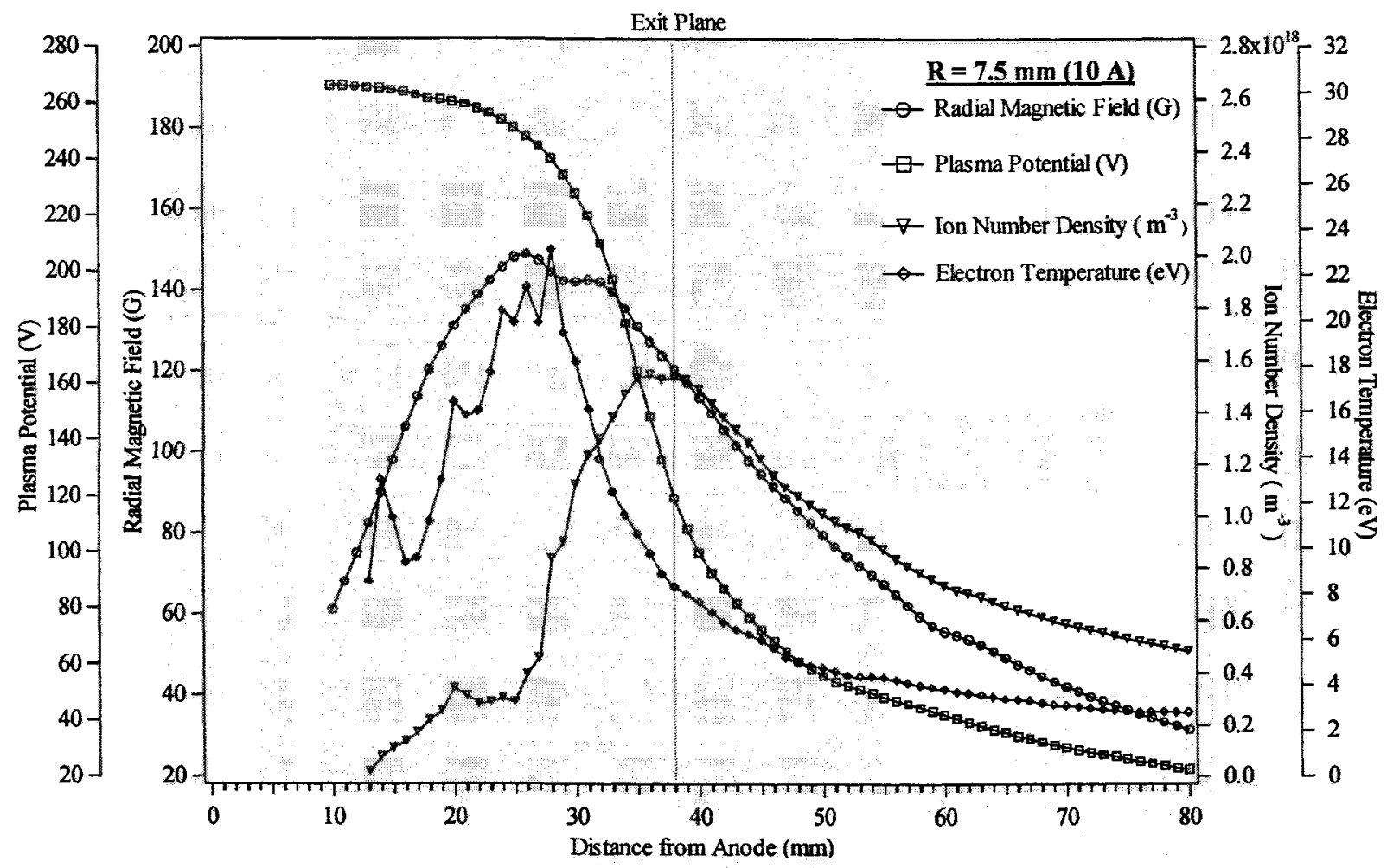

Figure 13. Radial magnetic field, plasma potential, ion number density, and electron temperature profiles in the discharge chamber at an operating condition of $300 \mathrm{~V}, 10 \mathrm{~A}$. These data correspond to a radial position $7.5 \mathrm{~mm}$ from the inner wall.

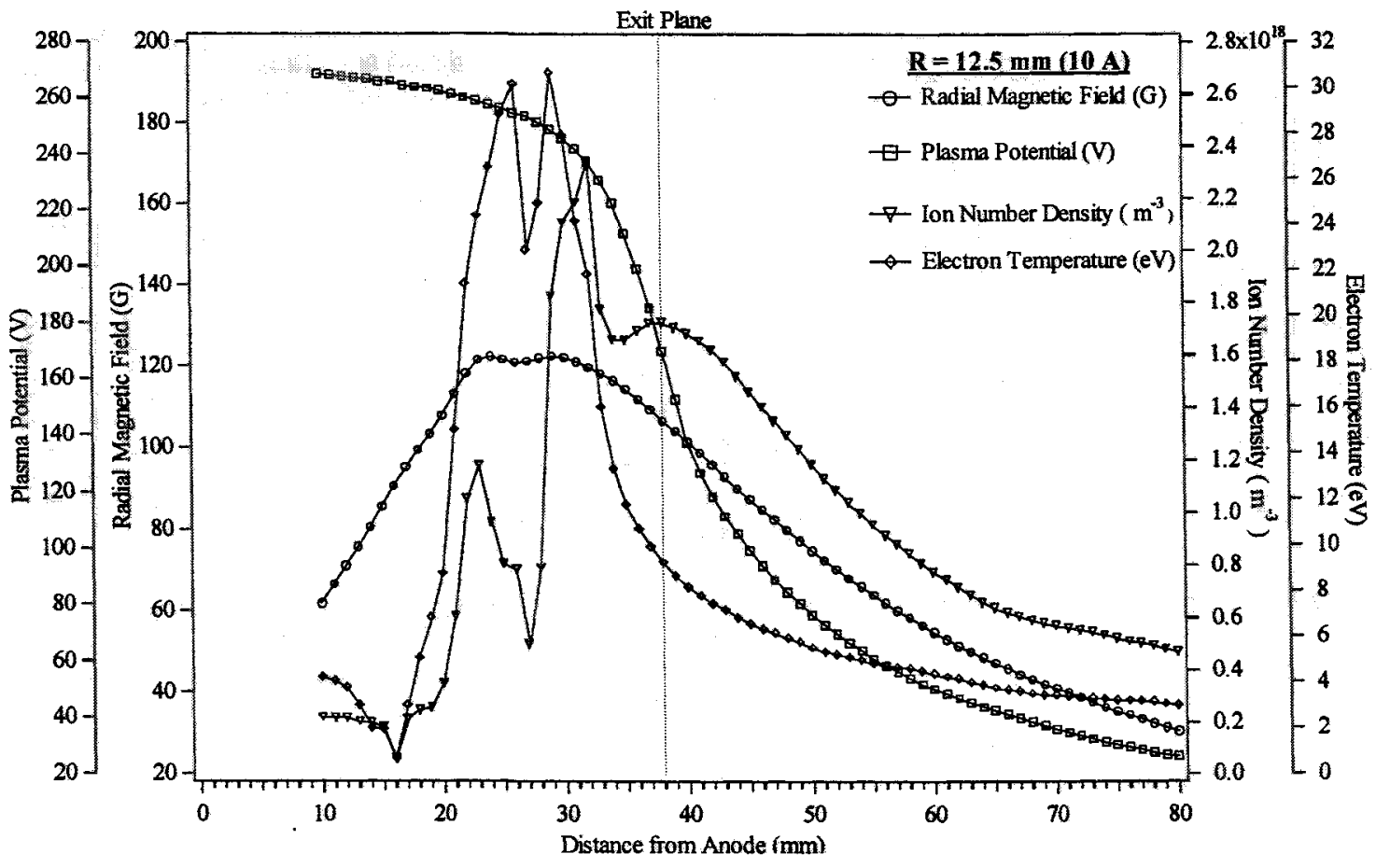

Figure 14. Radial magnetic field, plasma potential, ion number density, and electron temperature profiles in the discharge chamber at an operating condition of $300 \mathrm{~V}, 10 \mathrm{~A}$. These data correspond to a radial position $12.5 \mathrm{~mm}$ from the inner wall. 


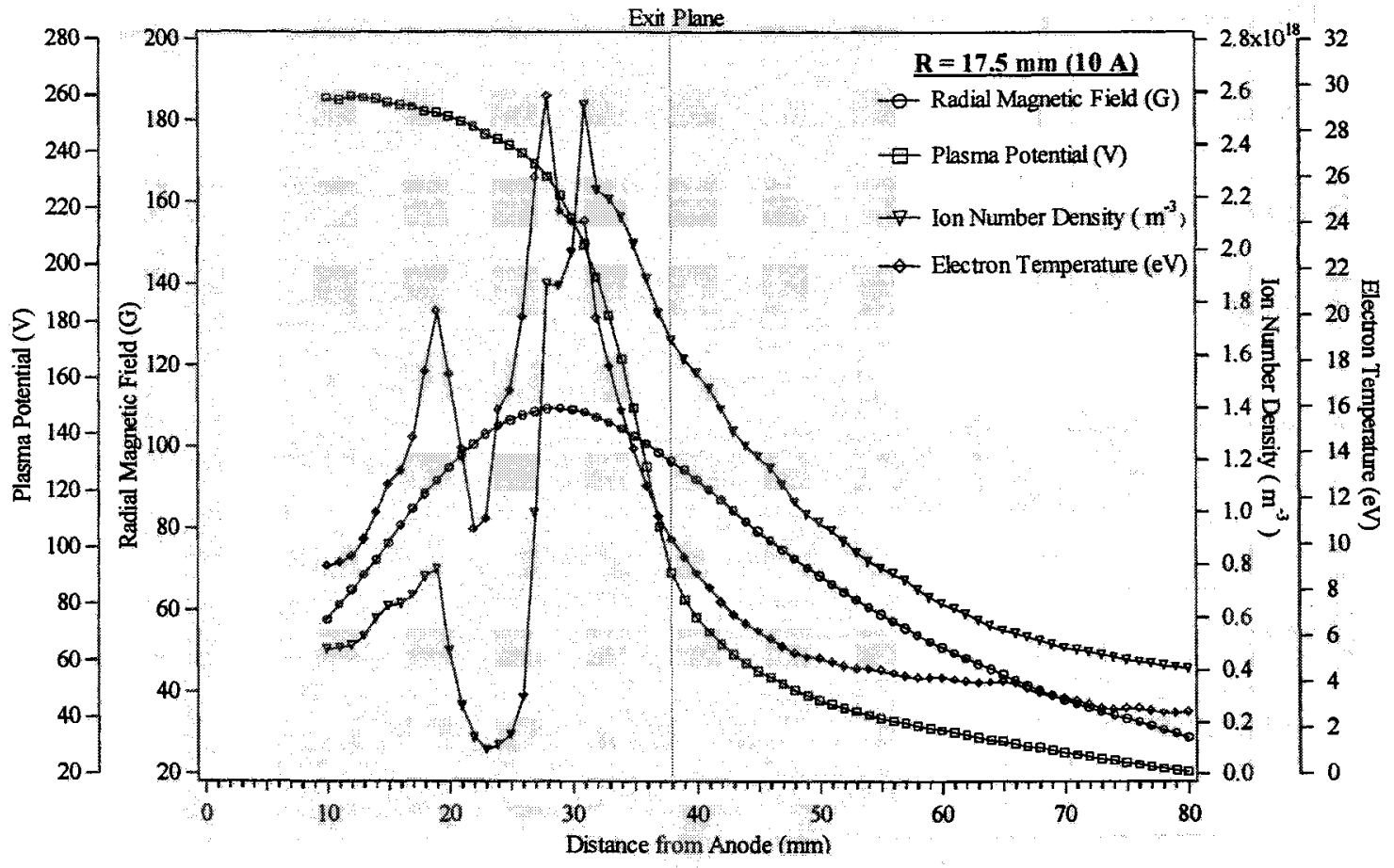

Figure 15. Radial magnetic field, plasma potential, ion number density, and electron temperature profiles in the discharge chamber at an operating condition of $300 \mathrm{~V}, 10 \mathrm{~A}$. These data correspond to a radial position $17.5 \mathrm{~mm}$ from the inner wall.

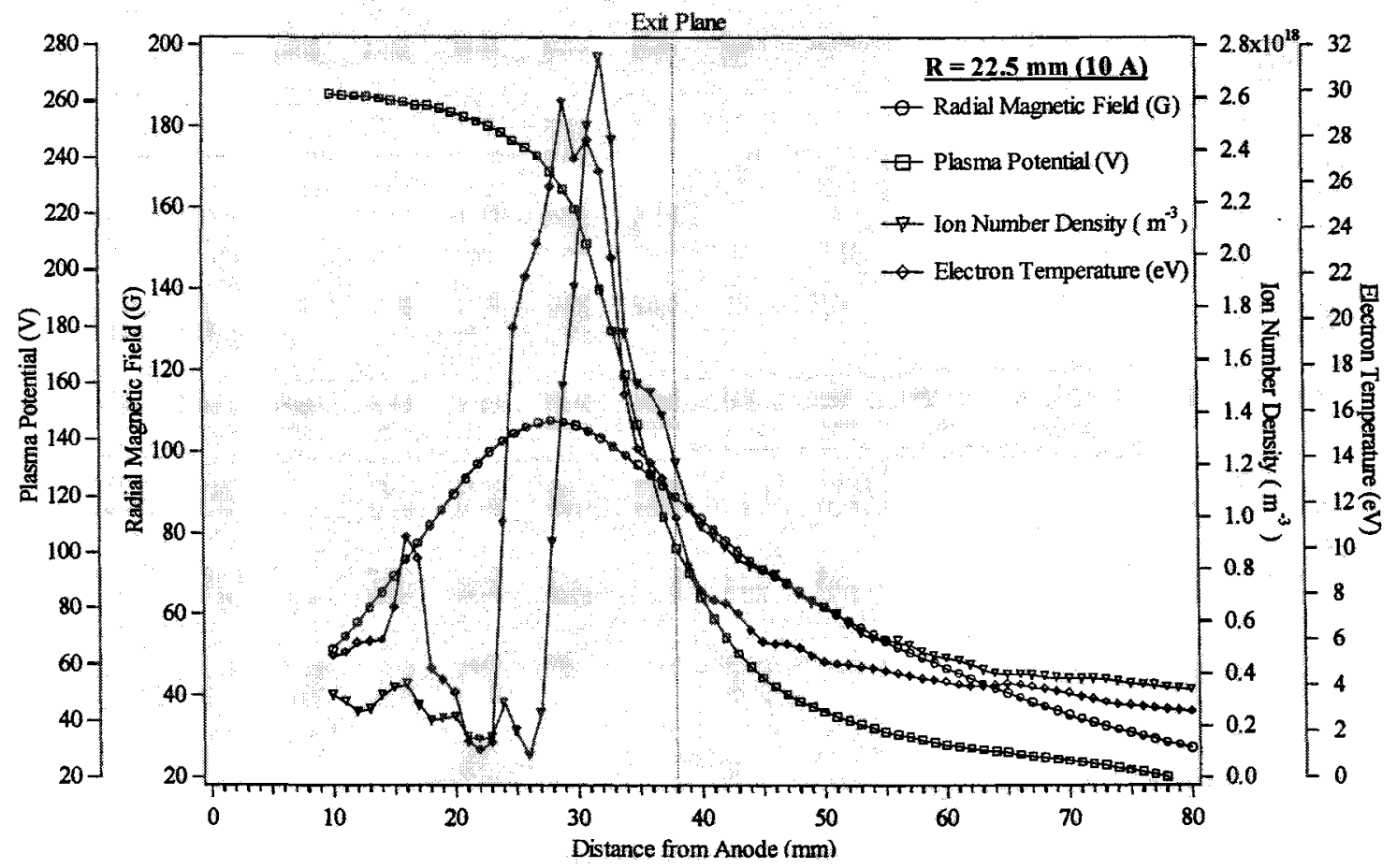

Figure 16. Radial magnetic field, plasma potential, ion number density, and electron temperature profiles in the discharge chamber at an operating condition of $300 \mathrm{~V}, 10 \mathrm{~A}$. These data correspond to a radial position $22.5 \mathrm{~mm}$ from the inner wall. 


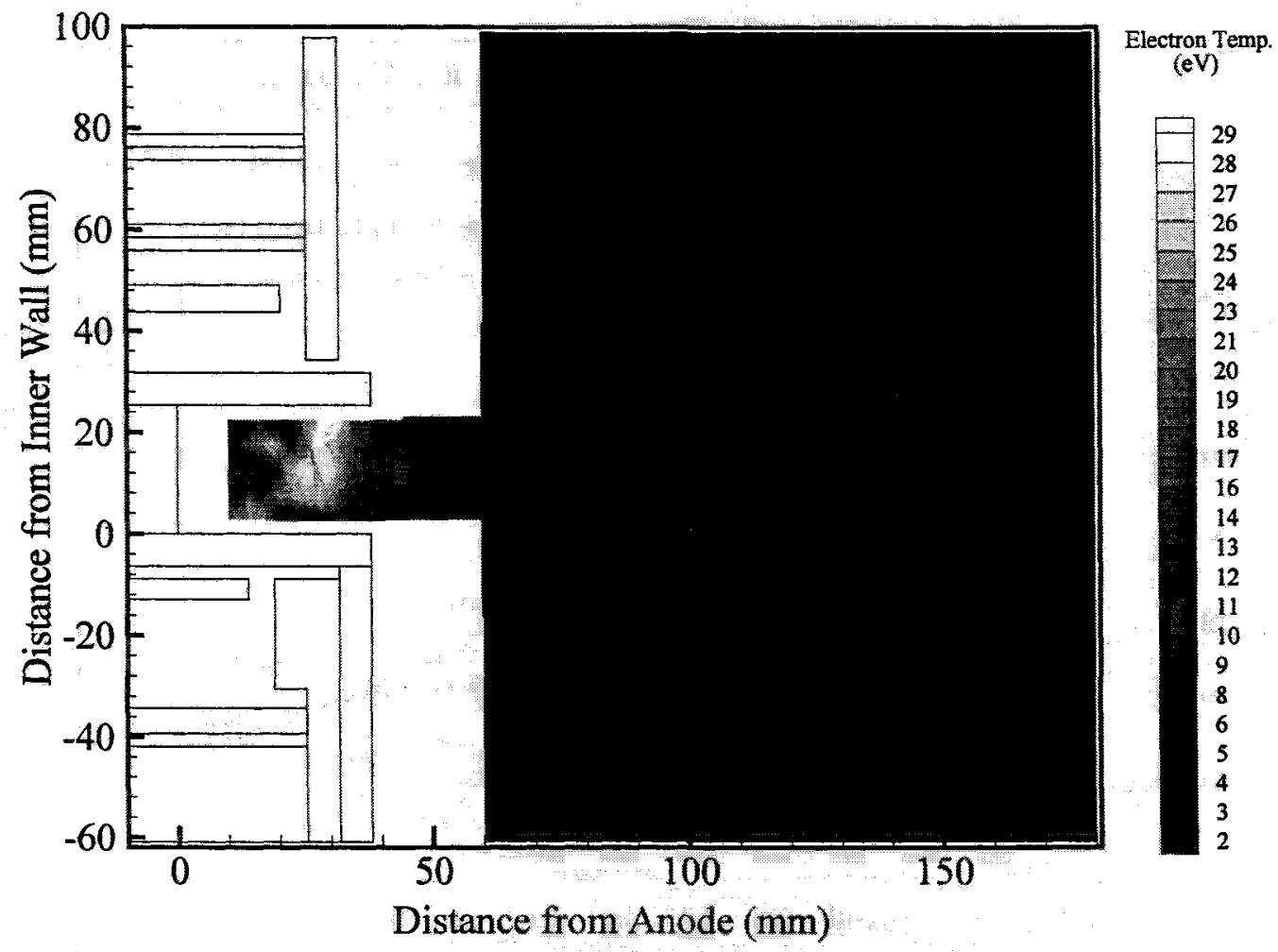

Figure 17. Contours of electron temperature at a thruster operating condition of $300 \mathrm{~V}$ and $10 \mathrm{~A}$.

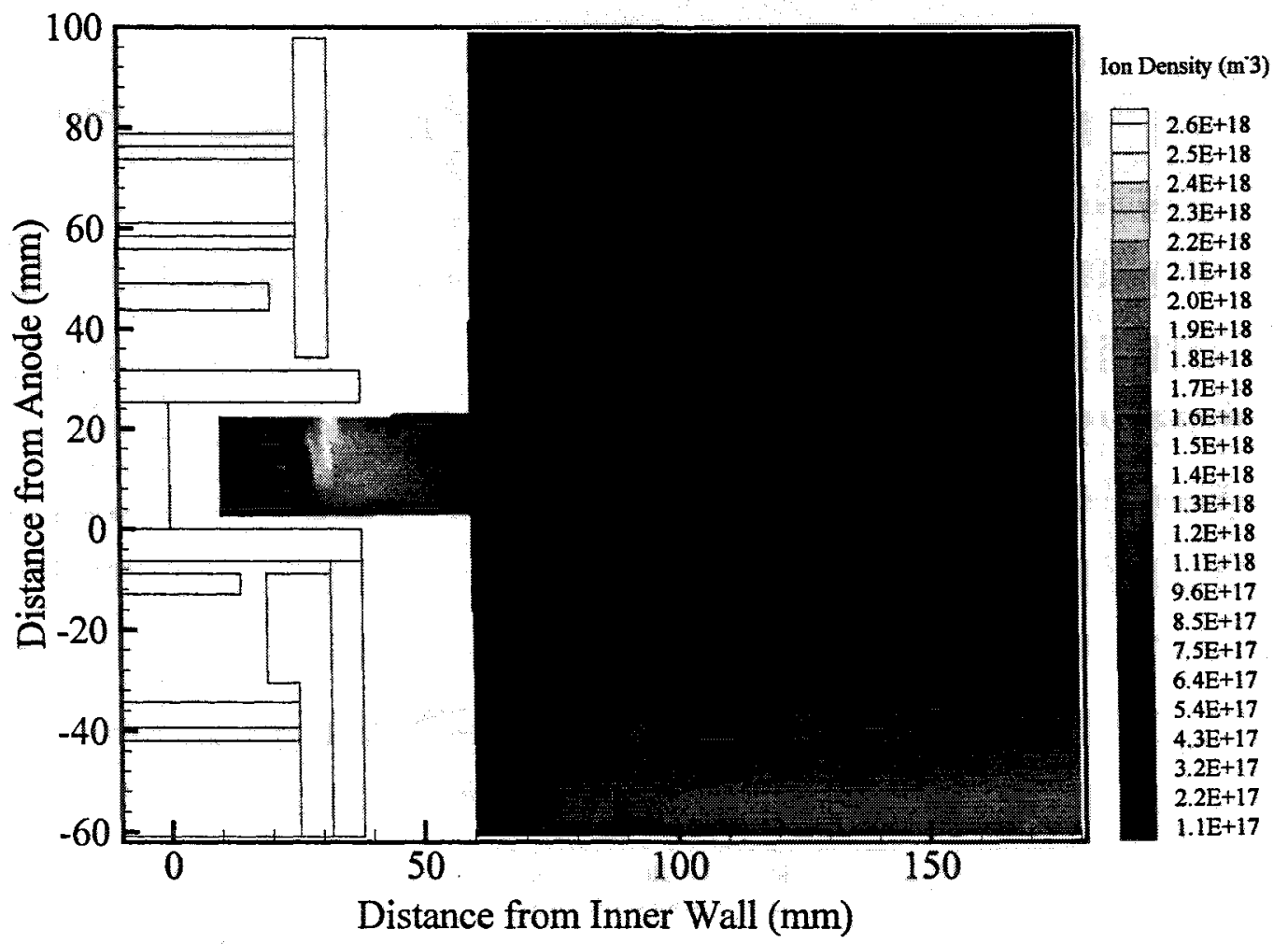

Figure 18. Contours of ion number density at a thruster operating condition of $300 \mathrm{~V}$ and $10 \mathrm{~A}$. 


\section{DISCUSSION}

\section{Ionization and Acceleration Zones}

The number density contour plot of Figure 11 illustrates the most striking feature of the $1.6 \mathrm{~kW}$ operating condition. The data exhibit, with the exception of the data along the inner wall, a doubleaxial-peak structure indicating two regions of ionization. The primary zone occurs quite far upstream of the exit plane $(-20 \mathrm{~mm})$ while the second occurs much closer to the exit plane $(\sim 32$ $\mathrm{mm}$ ). Referring back to Figures $7-10$, it can be seen that this primary ionization zone corresponds spatially with the peak electron temperature. The electron temperature begins to decrease considerably in the vicinity of the secondary peak, implying a different ionization mechanism. From the potential and magnetic field profiles, it was determined that this second ionization zone corresponds roughly to the location of high electron drift velocity, i.e. the Hall current. Figure 19 shows the axial profile of electron azimuthal energy.

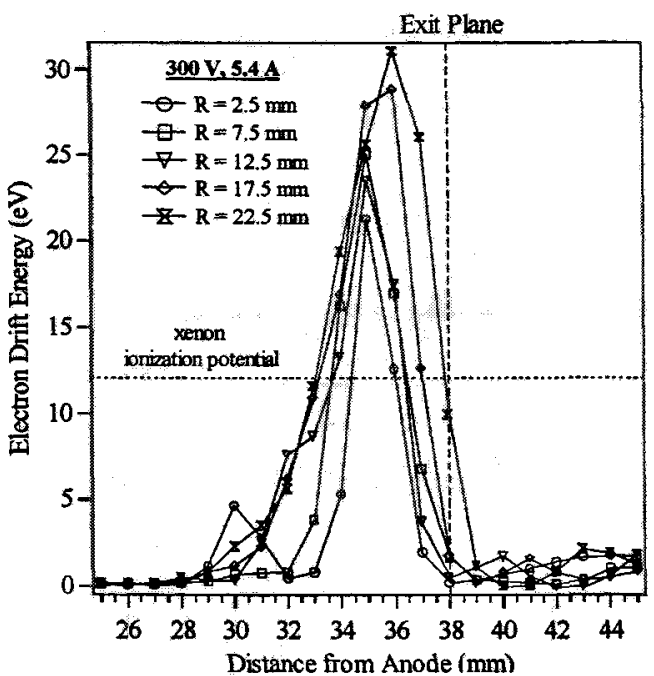

Figure 19. Equivalent electron drift energy axial profiles at $300 \mathrm{~V}, 5.4 \mathrm{~A}$. Drift energy is computed from the ExB drift velocity. The peak energy corresponds roughly to the secondary ionization zone shown by the local density increase near the exit plane in Figure 11.

The location of a main ionization peak far upstream of the exit plane helps to explain the lower efficiency of the P5 at low power. ${ }^{1}$ The ionization and acceleration zones are far apart and ions formed at this location see very little axial acceleration. This is evidenced by the low potential gradient in the primary ionization region. The result is a large loss of ions to the walls of the discharge channel. This is supported by observations of the erosion patterns in the P5 that show erosion of the boron nitride starting approximately $20 \mathrm{~mm}$ from the anode and extending to end of the channel. While the P5 is run at a number of different power levels, a majority of its run time is accrued at the $1.6 \mathrm{~kW}$ condition.

In contrast to the $1.6 \mathrm{~kW}$ case, data at the $3 \mathrm{~kW}$ condition show a single ionization zone very close to the acceleration region. The number density profiles follow very closely those of electron temperature, which is expected as the high temperature electrons are the main ionizing mechanism. Figure 18 shows the number density contours and it can be seen clearly that density peaks at an axial position of approximately $32 \mathrm{~mm}$. Referring back to the plasma potential profiles in Figures 12-16, this corresponds to the beginning of the main potential gradient. Obviously, this significantly reduces ion losses to the walls of the discharge channel since the ions are accelerated out of the thruster almost immediately after being formed. This would account for the increased efficiency compared to the $1.6 \mathrm{~kW}$ condition. $^{1}$

An interesting feature of the number density profile along the channel centerline, as shown in Figure 14, is the small secondary peak at the exit plane. As in the $1.6 \mathrm{~kW}$ case, the energy of the Hall current electrons is computed and the results are displayed in Figure 20. The electron drift energy peak for the centerline data corresponds very closely to the secondary density peak in Figure 14. If only single collisions are assumed, the drift energy appears too low to account for this additional ionization. However, the electron drift velocity is two orders of magnitude greater than the ion velocity. In the time it takes the relatively slow moving ions to traverse the acceleration zone, the electrons will have completed many cycles around the discharge channel. This greatly increases the probability of multiple collisions and offers an explanation for the secondary peak in Figure 14. The obvious question, then, is why this effect is not observed in the rest of the 10 A data. Referring back to Figures 12-16, the primary peak for the density data occurs several millimeters upstream of the exit plane $(-35-36 \mathrm{~mm})$, coinciding with the peak electron drift energy (with the exception of the centerline data) in Figure 20. The contribution of the Hall current would then be obscured by the primary ionization from high temperature electrons. 


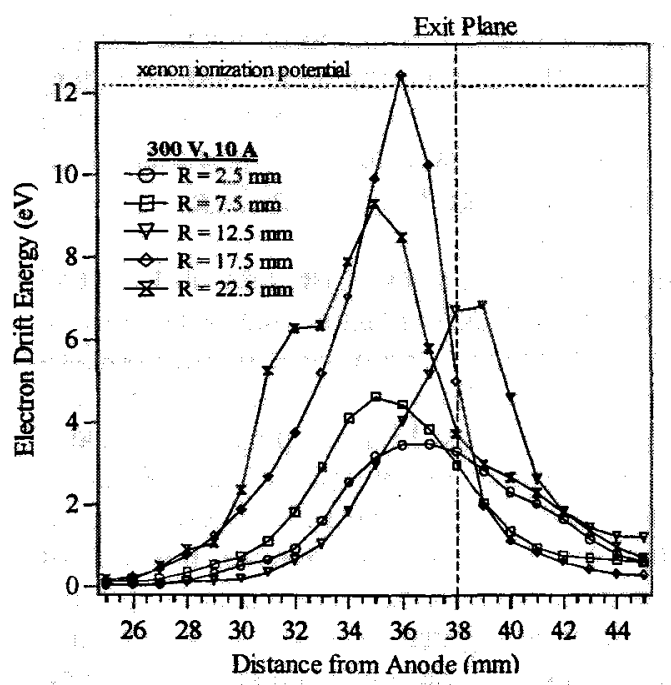

Figure 20. Equivalent electron drift energy axial profiles at $300 \mathrm{~V}, 10 \mathrm{~A}$. Drift energy is computed from the ExB drift velocity.

It is worth noting that both the $1.6 \mathrm{~kW}$ and $3 \mathrm{~kW}$ near-field number density data show very clearly the focusing of ions as they are accelerated out of the thruster. This high-density core is a defining characteristic of all Hall thrusters and is easily observed during operation. The electron temperature has dropped considerably in the near-field region and is quite uniform.

\section{Hall Parameter}

From the preceding discussion, it is apparent that the Hall current plays a significant role in thruster operation. A measure of the relative importance of the Hall current is the Hall parameter, which is defined as the ratio of electron gyrofrequency to electron collision frequency?

$$
\Omega=\frac{\omega}{v}=\frac{q B}{m n_{a} Q v}
$$

In equation (2), $\boldsymbol{\Omega}$ is the Hall parameter, $\omega$ is the electron gyrofrequency $\left(s^{-1}\right), v$ is the total electron collision frequency $\left(s^{-1}\right), q$ is the electron charge $\left(1.6 \times 10^{-19} \mathrm{C}\right), \mathrm{B}$ is the radial magnetic field $(\mathrm{T}), \mathrm{m}$ is the electron mass $\left(9.11 \times 10^{-31} \mathrm{~kg}\right), \mathrm{n}_{\mathrm{a}}$ is the neutral particle density $\left(\mathrm{m}^{-3}\right), \mathrm{Q}$ is the total electron crosssection, and $\mathrm{v}$ is the relative particle velocity.

The Hall parameter is of interest because it provides a measure of the cross-field motion (in this case azimuthal) of the electrons. For the condition $\Omega \gg 1$, the electrons complete many cyclotron gyrations before they undergo a collision. Therefore, the major component of the electron current is in the ExB direction.

For our calculations, an experimentally determined total collision cross-section for electrons in xenon was used. ${ }^{10}$ Neutral particle density was estimated from the mass flow rate assuming neutrals with a temperature of $1000 \mathrm{~K}^{9}$. The results for 1.6 $\mathrm{kW}$ and $3 \mathrm{~kW}$ are presented in Figures 21 and 22, respectively.

For both cases the Hall parameter is between 100 and 1000, with a few exceptions, indicating an azimuthal electron current component many times larger than the axial electron current. The points in Figure 22 exceeding 1000 are due to very low electron temperatures in the rear of the discharge channel It is interesting to note that the Hall parameter remains quite large $4-5$ centimeters downstream of the exit plane. Results presented by Choueiri", based on data from Bishaev and Kim" for a Russian built thruster, indicate electron Hall parameter values ranging from 10 to 1200 . Researchers at Stanford ${ }^{12}$ have reported Hall parameter values for their laboratory model Hall thruster in the 100-300 range.

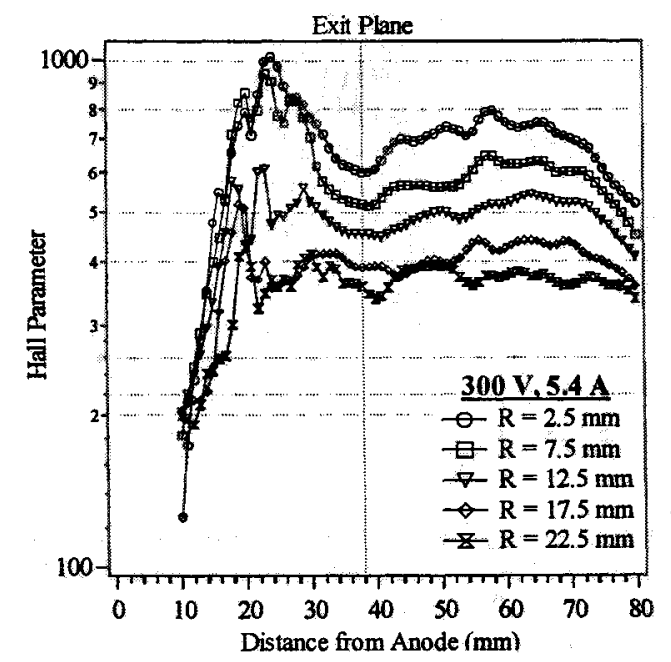

Figure 21. Electron Hall parameter for $300 \mathrm{~V}, 5.4 \mathrm{~A}$. 


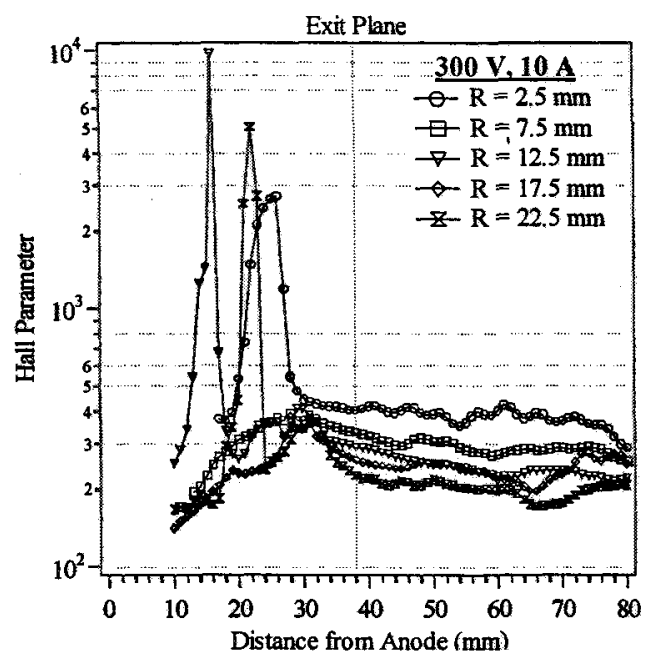

Figure 22. Electron Hall parameter for $300 \mathrm{~V}, 10 \mathrm{~A}$ case.

\section{ACKNOWLEDGEMENTS}

The authors would like to thank the PEPL staff for their invaluable assistance and moral support.

\section{REFERENCES}

1. Haas, J. M., Gulczinski, F. S., Gallimore, A. D., Spanjers, G.G., Spores, R.A.; "Performance Characteristics of a $5 \mathrm{~kW}$ Laboratory Hall Thruster," AIAA-98-3503, 34th Joint Propulsion Conference, Cleveland, $\mathrm{OH}$, July 12-15, 1998.

2. Haas, J.M., Hofer, R.R., and Gallimore, A.D., "Hall Thruster Discharge Chamber Plasma Characterization Using a High-Speed Axial Reciprocating Electrostatic Probe," AIAA-99-2426, 35th Joint Propulsion Conference, Los Angeles, CA, June 1999.

3. Tilley, D.L., et. al., "The Application of the Triple Probe Method to MPD Thruster Plumes," AIAA 90$2667,26^{\text {th }}$ Joint Propulsion Conference, July 1990.

4. Haas, J.M., and Gallimore, A.D., "Characterization of the Internal Plasma Structure of a $5 \mathrm{~kW}$ Hall Thruster," IEPC-99-078, 26th International Electric Propulsion Conference, Kitakyushu, Japan, October 1999.

5. Smith, B.A., and Overzet, L.J., "Improvements to the floating double probe for time-resolved measurements in pulsed rf plasmas," Rev. Sci. Instrum., Vol. 69, No. 3, p. 1372, March 1998.

6. Passoth, E., et. al., "An experimental study of plasma density determination by a cylindrical Langmuir probe at different pressures and magnetic fields in a cylindrical magnetron discharge in heavy rare gases," J. Phys. D., Vol.30, No.12, June 1997, p.1763-77.

7. Aikawa, H., "The Measurement of the Anisotropy of Electron Distribution Function of a Magnetized Plasma," J. Phys. Soc. Jap., Vol. 40, No. 6, June 1976.

8. Chung, P.M., et. al., "Electrostatic Probes in Stationary and Flowing Plasmas: Part 1. Collisionless and Transitional Probes," AIAA Journal, Vol. 12, No. 2, February 1974.

9. Choueiri, Edgar Y., "Characterization of Oscillations in Closed Drift Thrusters," AIAA 94-3013, 30 ${ }^{\text {th }}$ Joint Propulsion Conference, June 1994.

10. Brown, S.C., Basic Data of Plasma Physics. McGrawHill Book Company, New York, 1959.

11. Bishaev, A.M., and Kim, V., "Local plasma properties in a Hall-current accelerator with an extended acceleration zone," Soviet Physics, Technical Physics, 23(9):1055-1057, 1978.

12. Schmidt, D.P., et. al., "Operating Characteristics of a Linear Hall Thruster with an Open Electron-Drift," AIAA 99-2569, 35 ${ }^{\text {th }}$ Joint Propulsion Conference, June 1999. 